\title{
Book Review Global Apartheid: Refugees, Racism, and the New World Order
}

\author{
by Anthony H. Richmond \\ Oxford University Press, Toronto. 1994. 256 pp, \$22.95 \\ ISBN 0-19-541013 \\ Reviewed by Kathleen Valtonen
}

Anthony Richmond's topical work is a collection of essays that deal with the impact of postindustrialism, postmodernism, and globalization on international migration, racial conflict, and ethnic nationalism. Some of his previously published articles, in edited and updated form, are included, and they add depth to the current perspective. The content is organized into three sections: an extensive section on theory; analysis of the main issues with an emphasis on the multivariate nature of migration flows and ethnic relations, followed by comparisons of the policies and responses of Great Britain, the United States, and Australia with those of Canada; and the final section focuses on the priorities and dilemmas of the postindustrial era, and on prescriptive alternatives for the New World Order.

Richmond uses forcefully the analogy of apartheid to describe the strategy that is being adopted by the industrialized countries of Europe, North America, Australasia, and other wealthy enclaves that are seeking to protect themselves from what they perceive to be a singular threat to their territorial integrity and privileged lifestyles. This threat is posed by the in creasing pressure of international migration movements-mass migration from poorer to richer countries, from those where government systems have collapsed to those with more stable political environments. The scale of migration has grown and the nature of

Kathleen Valtonen is a visiting researcher at the Centre for Refugee Studies. She is working on her doctoral program at the Department of Social Policy, University of Turku, Finland, on refugee and immigrant resettlement in Finland and Canada. the flows has changed as a consequence of events and processes in our globalized, postindustrial society. It is estimated that 70 million persons live and work in other countries, and more than one million people emigrate permanently every year (UNFPA 1993). The fact that a majority of the $23 \mathrm{mil}$ lion refugees and displaced persons in the world today are from the Third World raises the question of racism, especially in the context of inhospitable responses by developed countries.

Richmond points out that while official apartheid in South Africa (the subject of some of his earlier work in plicit in policy instruments like the Schengen Agreement and the Dublin Convention.

The greatly accelerated rate of change brought about by technological advance (the revolution in communications being a salient example) has made possible closer linkages and interdependence in many areas. Incidents occurring in one place trigger a chain of events the effects of which are felt in countries far removed from the source. On the other hand, globalization has brought contradictions. The global economy is dominated by the interlinked economies of the United States, Europe, Japan, and the rapidly expanding ones of Taiwan, Hong Kong, and Singapore. A glaring contradiction in the current process of global change is that, while money, goods, and information flow relatively freely across borders, people do not. Migration pressures have resulted from shifts in the location of economic growth areas and from displacement caused by conflict. The main response

\section{The question is whether cultural pluralism is compatible with equality of opportunity and the coaptation of immigrants. As globalization proceeds, will heterogeneity persist, leading to de- territorialization of cultures, at the expense of homogeneity?}

1955 and 1961) is being dismantled, the rest of the world seems bent on constructing restrictive policies and instruments of control that bear remarkable resemblance to those fashioned in South Africain the 1950s. The reasons being advanced to justify imposition of systems of separation or "aparthood" have a familiar ring: defence of existing cultural and social institutions, state security, maintenance of law and order, the need to preserve ethnic identity, preservation of economic privilege, and the need to regulate and manage population movements. In our postindustrial society, the hedge of bitter wild almond planted by the Dutch colonials takes the form of armed frontier patrols, computer data banks, fingerprinting, travel documents, judicial hearings and, not least, the interdiction nets im- has been to try to stem the flow, to label as "illegal" or "undesirable" people who formerly would have been welcomed as useful workers or escapees from oppressive regimes. This rudimentary approach to a complex phenomenon inherent in the whole process of globalization does not address the situation. The fortress walls will be eroded: "[a] system of global apartheid is bound to fail" (p. 216).

In his book, Richmond takes up the challenge of providing a competent forum for the raising of many controversial issues that are otherwise at the forefront of current political discourse in Canada and elsewhere. Given the constraints imposed by the rapidity and unpredictability of change that make it difficult to assess the significance of phenomena he has, in my opinion, succeeded. He states, for ex- 
ample, that ethnic diversity is characteristic of almost all postindustrial societies. The question is whether cultural pluralism is compatible with equality of opportunity and the coaptation of immigrants. As globalization proceeds, will heterogeneity persist, leading to de-territorialization of cultures, at the expense of homogeneity?

While we are witnessing an era of change that is fraught with structural contradictions and a high potential for social conflict, we lack effective global governmental institutions. The United Nations "has failed dismally to prevent civil wars from occurring on all continents" (p. 223). How then can politicians, bureaucrats, and academics respond to the responsibility of formulating policies concerning peacekeeping, international migration, and refugee movements? At one of the few junctures in the book at which the author sets out concrete suggestions for proceeding in the New World Order, he states the imperative of dismissing as anachronistic all previous plans and programs. The whole system must be rethought in global terms and along the lines of international cooperation. Short-term self-interest must yield to policies promoting the long-term interest of all concerned, including the so-called developing countries, whose people must participate actively in making decisions that concern them.

Richmond argues that state sovereignty can no longer be maintained in an absolute way: "all boundaries are permeable and borders can no longer be defended with walls, iron curtains, armed guards, or computer surveillance systems" (p. 205). Sustainable development must be practised, and territories and their resources, material and human, must be held in trust for posterity.

Departing at times from the level of a largely structural analysis, the author links the preoccupation with territorial integrity and state sovereignty with individuals' "ontological security" needs and collective fears of loss of identity.
The author presents an extensive empirical analysis of the configurations of the present-day catalysts of social, economic, and political change that are at the root of regional instability and migration pressures: the legacy of colonialism, economic disparities between developed and developing countries, political confrontation between the superpowers, recent changes in Eastern Europe (the disintegration of the Soviet Union), the international arms bazaar. The reader should consult at an early stage the final chapter in which the author presents three alternative scenarios for the New World Order. In this way, the data in the thematic essays on, for example, "Racism and Immigration" and "Migration, Ethnic Conflict and the New World Order," can be more readily related to the typologies that facilitate the reader's own formulation of concrete alternatives in the New World Order. This is undoubtedly a process that the author intends to initiate.

The three scenarios are the nostalgic, the pragmatic, and the utopian. Significantly, the author has located the United Nations, its agencies, and Conventions within the realistic utopian alternative. At the end of the book the reader realizes that, as the author pointed out earlier, there is no exit from the global impasse. Because the author has so skilfully led the reader up to this point, the much less tangible nature of the alternatives indicated in the last chapter leaves the reader wishing for a more substantial closing to a dynamic work.

The author gives considerable weight to the theory underpinning the central issues and concepts, opening up for the student reader the parameters of academic scrutiny. This bookis an exhaustive contemporary work on the impact of globalization and postindustrialization on migration and ra$\mathrm{cial} / \mathrm{ethnic}$ conflict issues. Its wealth of empirical material, and the substantial body of relevant theory as well as policy implications, make it thoughtprovoking and recommended reading for students, policymakers, and researchers.

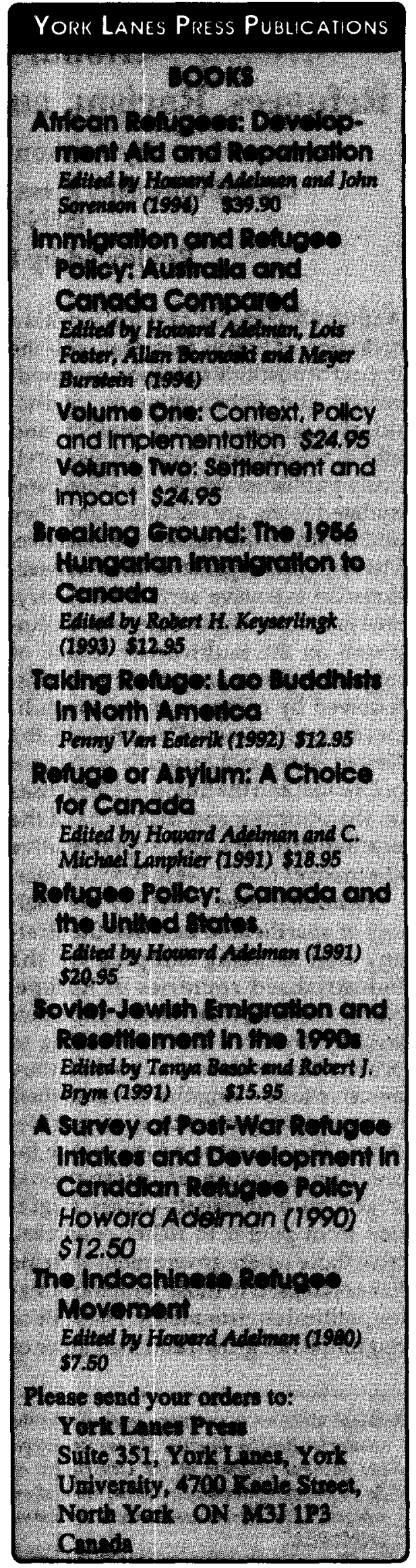




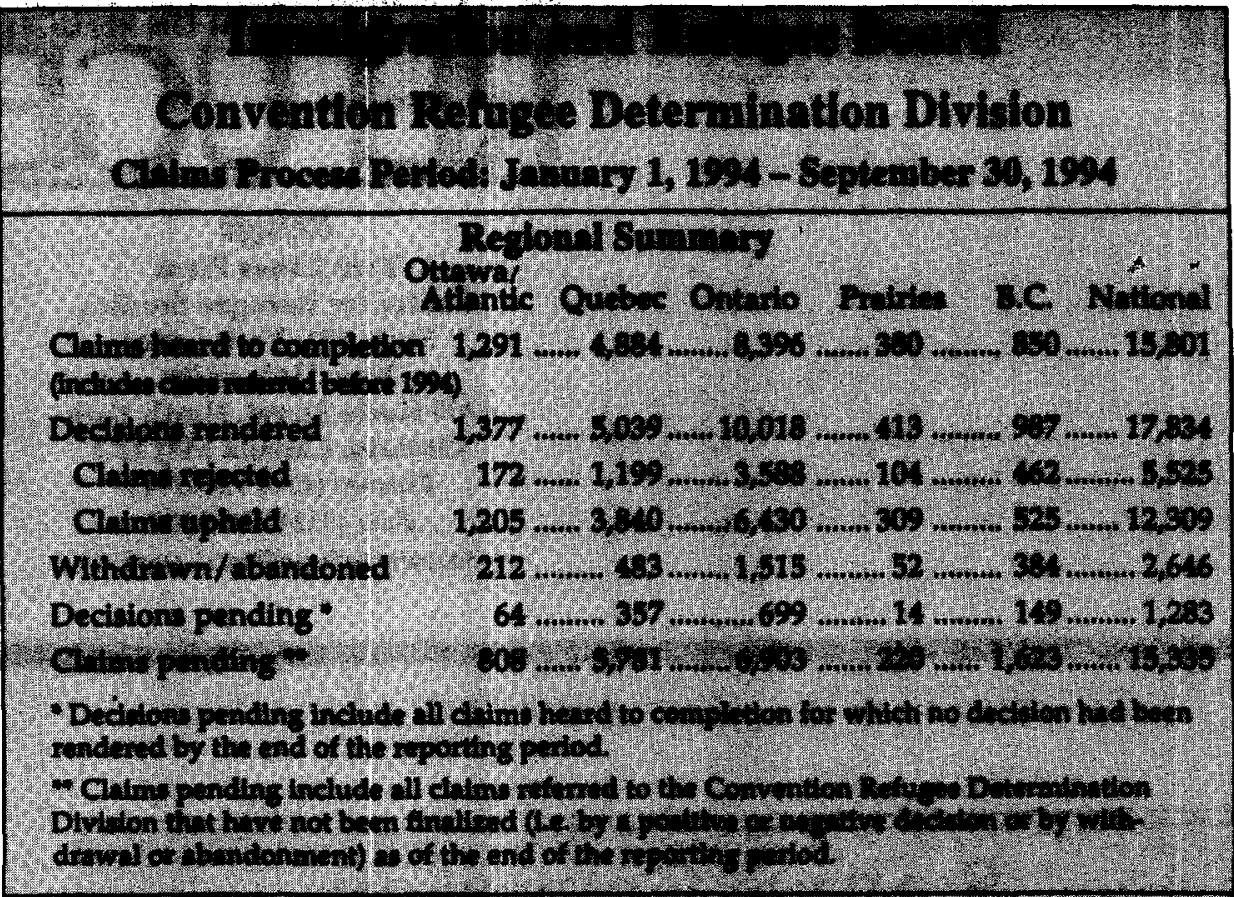

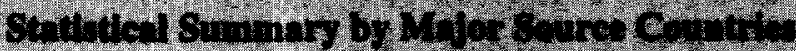

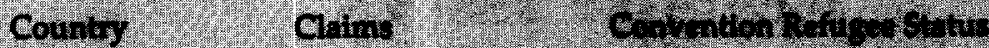

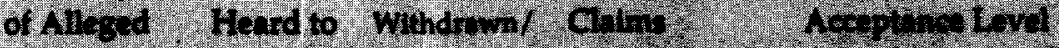

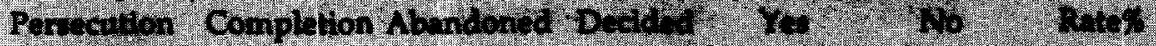
1. Srt Lenka
$2,106, \ldots+120$
2. Somili
2006.

.95
899............ 7
$736 \ldots . . . . . .253$
4. natio
890........... 72
3. hinel
498.............52
6. Bandedah
41........... 102
397..$--1 .-69$
373. ...... 51
$368, \ldots . . . . .67$
$354-213$
339. ............. 11
333 - . . . . . 15
398.
203............ 12
m $-2 .-19$
26 -
$11+4-24$
277 .
19.
20.
$106-2$
19 - -21.10
10........ 17
192.
t.
801

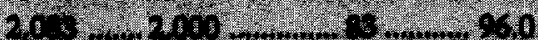
1000 - $821 .+2183+4-04$

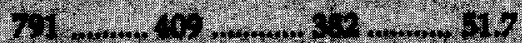

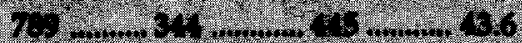

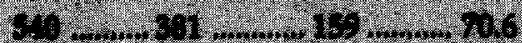

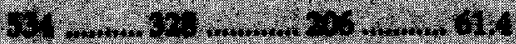

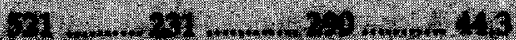
$172-313=159+663$
$370 .-218-2160 \ldots+-37.7$

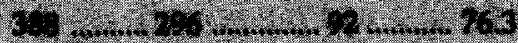

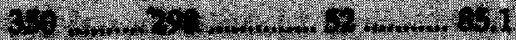

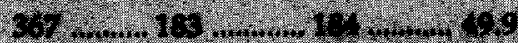
$303-303+\ldots-20$ - $30=910$

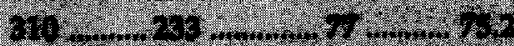

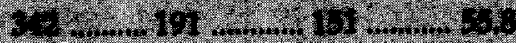

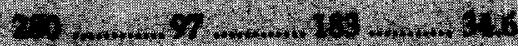

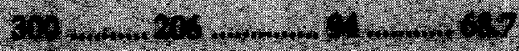

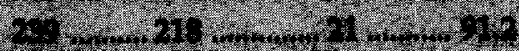

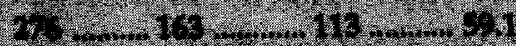

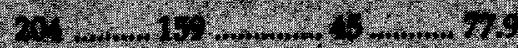

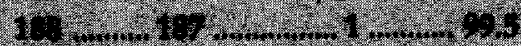

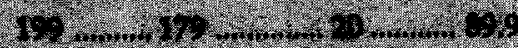

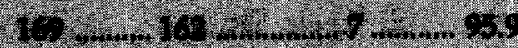

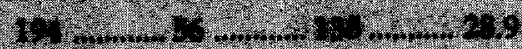

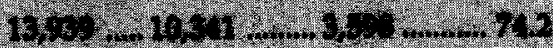

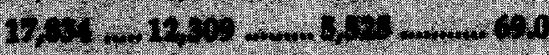

\section{Fortheoming Iitles}

CREYTork Lanes Press 1994-95

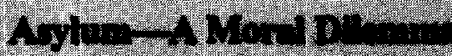

by Robu Cund r Rlat

(capulitiched with 6r monod Frcss)

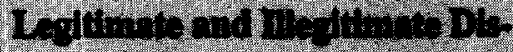

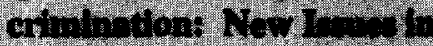
Editaby Foward the

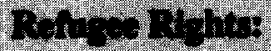

Repatcleco-pentestrves by fous C. Hothroy of John. Deat

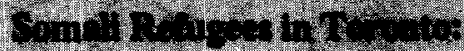
A roost by Ed ard Opolutes och

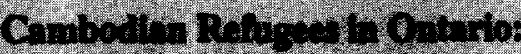

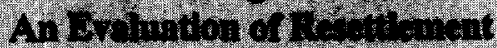
ond Raptation by Jond Mciellan

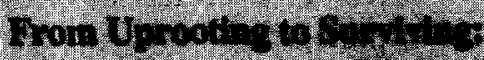

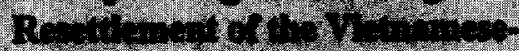

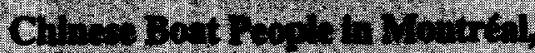
$150 \times 20$ by Larnt Lan

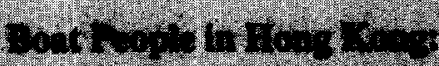

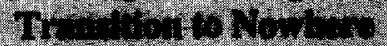
by Lention

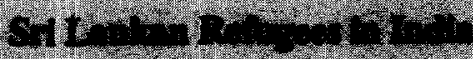
bytimans:

A wushed by

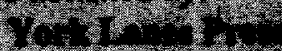

Sille 351, Yorkt

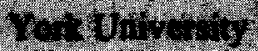

thoureelo sinet

Nortir rot on wartes Cindia

Fut:(416) 736-5097

Intcriet:

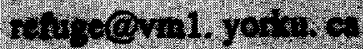




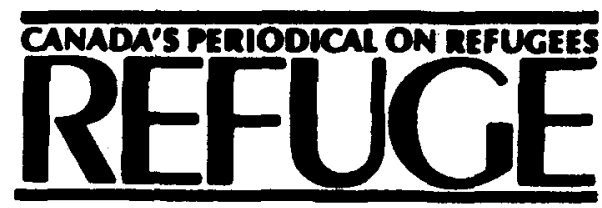

Refuge

York Lanes Press

Centre for Refugee Studies

Suite 351, York Lanes

York University

4700 Keele Street, North York

Ontario, Canada M3J 1P3

Phone: (416) 736-5843

Fax: (416) 736-5837

Internet: refuge@vm1.yorku.ca

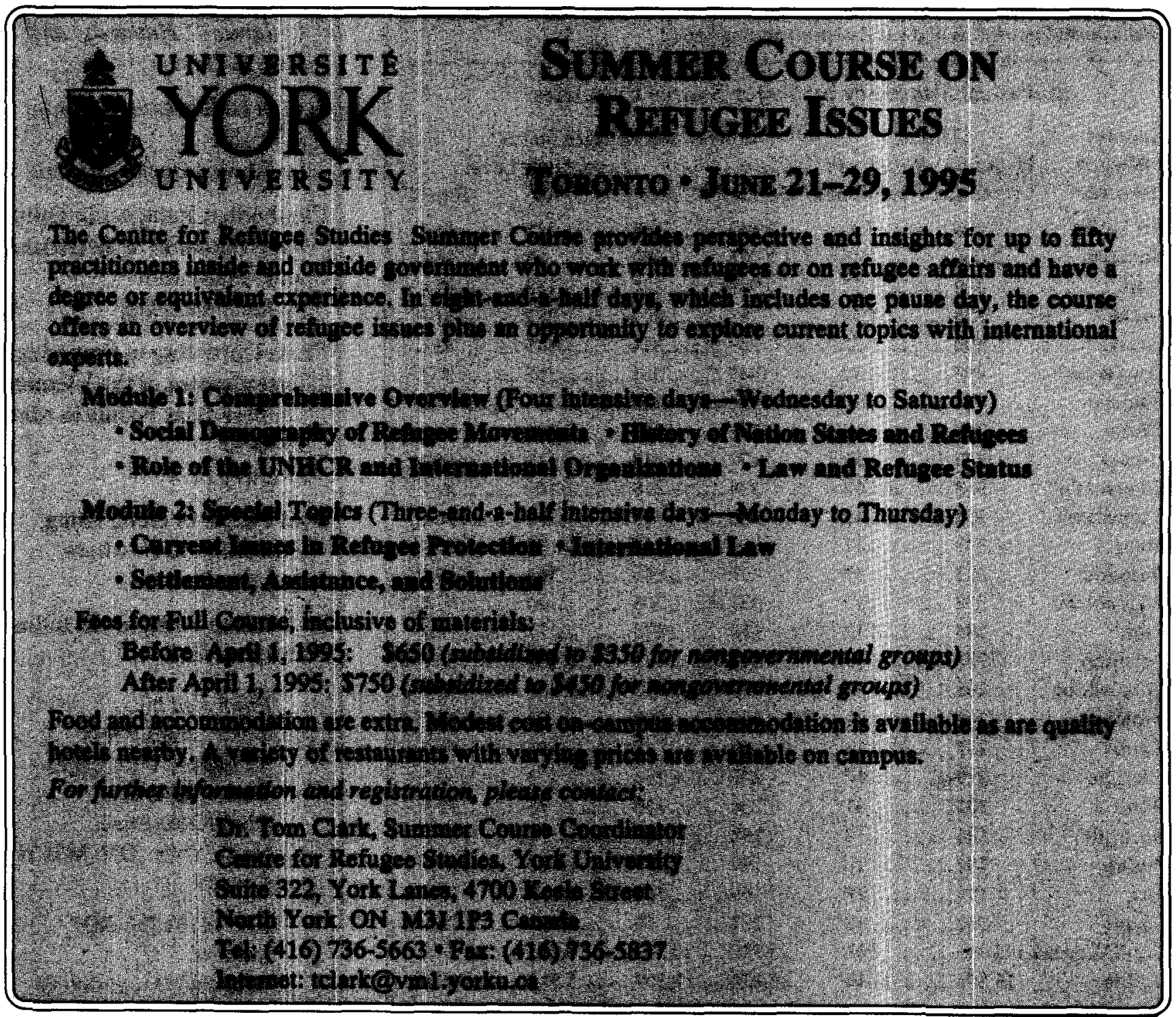

